\title{
The multifaceted roles of metabolic enzymes in the Paracoccidioides species complex
}

\section{Caroline M. Marcos, Haroldo C. de Oliveira, Julhiany de F. da Silva, Patrícia A. Assato, Ana M. Fusco-Almeida and Maria J. S. Mendes-Giannini*}

Laboratório de Micologia Clínica, Departamento de Análises Clínicas, Faculdade de Ciências Farmacêuticas, Universidade Estadual Paulista, Araraquara, Brazil

\section{Edited by:}

Helio K. Takahashi, Universidade

Federal de São Paulo, Brazil

\section{Reviewed by:}

Marcelo Tolmasky, California State University, Fullerton, USA

Marcos Sergio Toledo, Universidade Federal de São Paulo, Brazil

\section{*Correspondence:}

Maria J. S. Mendes-Giannini, Laboratório de Micologia Clínica, Departamento de Análises Clínicas, Faculdade de Ciências Farmacêuticas, Universidade Estadual Paulista, Rodovia Araraquara-Jaú, Km 1, Araraquara, São Paulo, Brazil e-mail:giannini@fcfar.unesp.br

\begin{abstract}
Paracoccidioides species are dimorphic fungi and are the etiologic agents of paracoccidioidomycosis, which is a serious disease that involves multiple organs. The many tissues colonized by this fungus suggest a variety of surface molecules involved in adhesion. A surprising finding is that most enzymes in the glycolytic pathway, tricarboxylic acid (TCA) cycle and glyoxylate cycle in Paracoccidioides spp. have adhesive properties that aid in interacting with the host extracellular matrix and thus act as 'moonlighting' proteins. Moonlighting proteins have multiple functions, which adds a dimension to cellular complexity and benefit cells in several ways. This phenomenon occurs in both eukaryotes and prokaryotes. For example, moonlighting proteins from the glycolytic pathway or TCA cycle can play a role in bacterial pathogenesis by either acting as proteins secreted in a conventional pathway and/or as cell surface components that facilitate adhesion or adherence. This review outlines the multifunctionality exhibited by many Paracoccidioides spp. enzymes, including aconitase, aldolase, glyceraldehyde-3-phosphate dehydrogenase, isocitrate lyase, malate synthase, triose phosphate isomerase, fumarase, and enolase. We discuss the roles that moonlighting activities play in the virulence characteristics of this fungus and several other human pathogens during their interactions with the host.
\end{abstract}

Keywords: Paracoccidioides spp., moonlighting proteins, virulence, glycolytic pathway and tricarboxylic acid cycle, glyoxylate cycle, adhesins

\section{INTRODUCTION}

A great challenge in studying proteins is understanding how encoded proteins function and interact with each other to coordinate essential cellular processes. Although many protein roles can be inferred by homology-based function predictions, this approach may be complicated for multifunctional proteins. The notion that one gene encodes one protein and results in only one function is outdated because proteins may have multiple functions (including on a single polypeptide chain), and the function may change based on external signals (Kirschner and Bisswanger, 1976; Jeffery, 1999; Wolff and Arnau, 2002; Jeffery, 2009; Pandini et al., 2012; Wienkers and Rock, 2014).

Multiple binding sites or changes in unusable regions of a protein structure may produce a new function because many proteins seem larger than necessary to perform only one function at a single binding site. These multifunctional proteins may benefit an organism because synthesizing fewer proteins may save cellular energy for additional functions, such as growth and reproduction (Jeffery, 1999).

Moonlighting proteins are exceptional multifunctional proteins; these multifunctional proteins can perform several additional functions that are often unrelated. These functions are typically independent, which means that if one function is inactivated, due a mutation, for example, the second function is unaffected (Huberts and van der Klei, 2010). The function of a moonlighting protein can vary based on changes in cellular location or expression, cell type, association between two or more polypeptide chains and the cellular levels of a ligand, substrate, cofactor, product, or different binding sites (Jeffery, 2003a); moonlighting cannot be attributed to hybrid genes, which are single genes that code for multiple proteins or polypeptides that express different functions after protease cleavage (Kainulainen and Korhonen, 2014). Moonlighting functions have been demonstrated by multiple independent studies with unexpected phenotypes, locations, and binding partners (Copley, 2012).

The steady increase in new proteins characterized as multifunctional supports the potential importance of in-depth studies on the mechanism underlying these moonlighting functions in the same cell. (Chung et al., 1999; Jeffery, 1999, 2003a). Moonlighting may be due to joint engineering of communication and cooperation for various functions and paths in a complex cell or different cell types in an organism (Jeffery, 2003b).

Multifunctional proteins are present in prokaryotes and eukaryotes, such as mammals, which compound the protein arsenal of these organisms (Clarke et al., 2001; James and Viola, 2002; Brilli and Fani, 2004; Orita et al., 2005). The moonlighting activities of one protein are typically in addition to their role in chemical metabolic reactions, which demonstrates that these proteins are highly variable; metabolic enzymes can perform double duty as transcription factors, participate in assembly or autophagy, or maintain the levels of oxidative phosphorylation in the cells through maintaining mitochondrial DNA, among other functions (Chen et al., 2005; Gancedo and Flores, 2008). Intriguingly, in many cases, these proteins are constitutively expressed at low levels 
and act as enzymes, but when they are expressed at high levels, they perform moonlighting functions (Baker, 1991; Gómez et al., 2011).

Although highly conserved proteins perform many moonlighting functions, moonlighting functions cannot be predicted based on sequence and structural comparisons. Researchers speculate that evolution produced proteins with almost identical structures but different functions because moonlighting may provide a means to expand the functional capabilities of an organism without a genome-wide expansion (Kelkar and Ochman, 2013). Researchers have proposed that a protein must have some inherent compatibility for a new function to develop a moonlighting function (Aharoni et al., 2005).

To identify the moonlighting site or sites, we must first study how the moonlighting protein evolved and how the moonlighting function is related to the original "active site" (Henderson and Martin, 2011). Certain moonlighting proteins are recruited to the cell surface and involved with pathogenic processes (Pancholi and Chhatwal, 2003; Wang et al., 2013). This process not only occurs in bacteria but also in fungi, including the Paracoccidioides genus. Moonlighting proteins may relocate to the bacterial surface and present adhesion activities specific for host cell targets. These adhesive activities in moonlighting proteins have been widely studied and seem to play important roles in bacterial adhesion and colonization (Wang et al., 2013). Most abundant moonlighting adhesins are proteins that interact with the adhesion complex through binding fibronectin, which is a protein present at high concentrations in the fluids between cells and in the extracellular matrix (ECM), and it links cells to the ECM through specific transmembrane receptors (Henderson and Martin, 2011).

Examples of secondary functions associated with catalysis have been reported in many organisms, including plants (Moore, 2004), animals (Sriram et al., 2005), yeast (Gancedo and Flores, 2008), and prokaryotes (Jeffery, 1999, 2004). In bacteria, the glycolytic enzymes glyceraldehyde-3-phosphate dehydrogenase (GAPDH) and enolase (ENO) as well as the chaperonin 60, Hsp70, and peptidyl-prolyl isomerase most commonly exhibit moonlighting functions during bacterial virulence, such as adhesion and modulation of host cell signaling processes (Henderson and Martin, 2011). Most examples have been demonstrated in yeast (Gancedo and Flores, 2008) likely because it is the best understood and an extensively studied model organism. The known moonlighting functions are extremely diverse and involved in several biological functions. Examples of well-characterized moonlighting proteins in Paracoccidioides spp. and other fungal species are shown in Table 1.

Many currently known moonlighting proteins are highly conserved enzymes present in many different organisms (FothergillGilmore and Michels, 1993; Jeffery, 1999). Among these proteins, we highlight the enzymes involved in sugar metabolism (Hendriks et al., 1988; Wistow et al., 1988; Yuan et al., 1997; Chen et al., 2005; Decker and Wickner, 2006; Lu et al., 2007). Researchers have also suggested that most enzymes in the glycolytic pathway and tricarboxylic acid (TCA) cycle have moonlighting functions (Kim and Dang, 2005; Sriram et al., 2005). Moreover,
Commichau et al. (2009) showed interactions between glycolytic enzymes and proteins involved in RNA degradation, which suggests the presence of additional moonlighting functions for these proteins.

In this review, we discuss multiple attributes of moonlighting proteins in Paracoccidioides spp. and indicate the studies that justify their inclusion in this category. Another goal of this review is to highlight the importance of this phenomenon and its wide implications for both basic and applied research.

\section{MOONLIGHTING Paracoccidioides SPECIES COMPLEX PROTEINS}

Studies have characterized the ECM components involved in interactions between Paracoccidioides spp. and the host. This genus is composed of two species, Paracoccidioides lutzii and P. brasiliensis; the latter is sub-classified into three different phylogenetic groups. The large number of tissues that this fungus can colonize and infect suggests that it includes many cell adhesins. Certain molecules from Paracoccidioides spp. were identified as ligands for ECM components (Mendes-Giannini et al., 2008). Gp43 was the first molecule identified as a laminin-binding protein (Vicentini et al., 1994; Hanna et al., 2000). Additional binding affinity assays have shown that gp43 can bind both fibronectin and laminin. In Paracoccidioides spp, certain additional adhesins have also been described and may play an important role in pathogenesis (Andreotti et al., 2005; González et al., 2005; Barbosa et al., 2006; Mendes-Giannini et al., 2006; Pereira et al., 2007; Donofrio et al., 2009).

Several studies in Paracoccidioides spp. show that many metabolic enzymes may play a role in virulence. The most commonly identified moonlighting functions of Paracoccidioides spp. include functions related to adhesion and ECM-binding activity. Enzymes in the glycolytic pathway and TCA cycle act as moonlighting proteins in Paracoccidioides spp, including GAPDH, ENO, and fructose-1-6-bisphosphate aldolase (FBA); each displays different affinities for binding ECM components. Additionally, malate synthase (MLS) and isocitrate lyase (ICL) from the glyoxylate pathway as well as aconitase (ACO) from the TCA cycle may have multifunctional roles, including during the interaction between the fungus and host (da Silva Neto et al., 2009; Brito et al., 2011; Cruz et al., 2011). Figure 1 shows examples of moonlighting proteins described in Paracoccidioides spp.

Moonlighting functions have been increasingly recognized in glycolytic pathway and TCA cycle enzymes. In particular, despite lacking identifiable secretion signals, glycolytic enzymes have been observed on the Paracoccidioides surface, where they exhibit various functions that are unrelated to glycolysis, including a direct interaction with the host's soluble proteins and surface ligands. Certain Paracoccidioides spp. proteins translocate to the exterior through unconventional protein secretion mechanisms, such as an affinity between certain proteins that act as transport vesicle coat components, which eventually lead to adherence or internalization and delivery to a distinct endosomal compartment in secretory vesicles (Nombela et al., 2006). This process involves vesicles derived from inward membrane invagination (endosomes), which results in protein trafficking to the plasma membrane and/or extracellular space, controlling localization and/or activity (Keller 
Table 1 | Moonlighting proteins characterized in different fungal species.

\begin{tabular}{|c|c|c|c|c|}
\hline Proteins & $\begin{array}{l}\text { Metabolic pathway } \\
\text { or function }\end{array}$ & Moonlighting function & Fungal species & Reference \\
\hline \multirow[t]{6}{*}{ Enolase } & Glycolysis & Thermal tolerance and growth control & Saccharomyces cerevisiae & Sekita et al. (1985) \\
\hline & & Invasion process; cell wall construction & Candida albicans & $\begin{array}{l}\text { Walsh etal. (1991), van Deventer } \\
\text { etal. (1994), Angiolella etal. (1996) }\end{array}$ \\
\hline & & Invasion process (plasminogen binding) & C. albicans; Aspergillus & Eroles et al. (1997), Fox and Smulian \\
\hline & & & fumigatus; Paracoccidioides & (2001), Jong etal. (2003), Nogueira \\
\hline & & & spp. & etal. (2010), Marcos etal. (2012) \\
\hline & & Adhesion process (fibronectin binding) & Paracoccidioides spp. & $\begin{array}{l}\text { Donofrio etal. (2009), Marcos etal. } \\
\text { (2012) }\end{array}$ \\
\hline Malate synthase & Glyoxylate cycle & $\begin{array}{l}\text { Adhesion process (type I and IV } \\
\text { collagen and fibronectin binding) }\end{array}$ & Paracoccidioides spp. & da Silva Neto et al. (2009) \\
\hline \multirow[t]{2}{*}{ Aconitase } & TCA cycle & Mitochondrial DNA maintenance & S. cerevisiae & $\begin{array}{l}\text { Albring etal. (1977), Rouault et al. } \\
\text { (1991), Lu et al. (2001), Chen etal. } \\
\text { (2005), Myers (2009) }\end{array}$ \\
\hline & & Iron regulatory protein & $\begin{array}{l}\text { Paracoccidioides spp., } \\
\text { S. cerevisiae }\end{array}$ & $\begin{array}{l}\text { Narahari etal. (2000), da Fonseca } \\
\text { etal. (2001), Barbosa etal. (2004) }\end{array}$ \\
\hline \multirow[t]{3}{*}{ Aldolase } & Glycolysis & Invasion process (plasminogen binding) & C. albicans, Paracoccidioides & Burucoa etal. (1995), McCarthy \\
\hline & & & spp. & et al. (2002), Pitarch etal. (2002), \\
\hline & & & & Crowe etal. (2003), Chaves (2013) \\
\hline \multirow[t]{4}{*}{ GAPDH } & Glycolysis & Adhesion and invasion processes & C. albicans & Pancholi and Fischetti (1992), \\
\hline & & (fibronectin, laminin and & & Gil-Navarro et al. (1997), Delgado \\
\hline & & plasminogen-binding) & & etal. (2003), Starnes etal. (2009) \\
\hline & & $\begin{array}{l}\text { Adhesion process (laminin, fibronectin } \\
\text { and type I collagen binding) }\end{array}$ & Paracoccidioides spp. & Barbosa et al. (2006) \\
\hline \multirow[t]{2}{*}{ Isocitrate Iyase } & Glyoxylate cycle & Growth & Aspergillus fumigatus & $\begin{array}{l}\text { Gainey etal. (1992), Valenciano et al. } \\
\text { (1996), Ebel etal. (2006) }\end{array}$ \\
\hline & & $\begin{array}{l}\text { Adhesion process (fibronectin and type } \\
\text { IV collagen binding) }\end{array}$ & Paracoccidioides spp. & Cruz et al. (2011) \\
\hline $\begin{array}{l}\text { Triose phosphate } \\
\text { isomerase }\end{array}$ & Glycolysis & $\begin{array}{l}\text { Adhesion process (laminin and } \\
\text { fibronectin binding) }\end{array}$ & Paracoccidioides spp. & $\begin{array}{l}\text { da Fonseca etal. (2001), Pereira } \\
\text { etal. }(2004,2007)\end{array}$ \\
\hline
\end{tabular}

et al., 2006; Nosanchuk et al., 2008; Oliveira et al., 2010; Rodrigues et al., 2014). Straus et al. (1996) first demonstrated protein transport in vesicles in P. brasiliensis. Longo et al. (2014) identified many $P$. brasiliensis surface proteins in extracellular vesicles, which suggests participation of these structures in the fungal secretome and cell wall metabolism. Extracellular vesicles produced by fungi mostly contain proteins related to diverse metabolic processes. In Paracoccidioides spp., GAPDH, ENO, TPI and FBA were identified in the vesicle proteome and were microscopically localized to the cell wall as well as implicated in adhesion to ECM components (Vallejo etal., 2012). These results explain the reports for numerous cytoplasmic proteins, wherein the proteins perform other functions outside the plasma membrane, both in the cell wall and extracellular environment.

Another aspect for consideration is the immunological role of fungal surface proteins; these proteins may interact with the host in numerous ways and modulate the immune response (Travassos and Taborda, 2012). For example, the recognition of cell wall-associated proteins by pre-activated $\mathrm{T}$ cells and/or antibodies may interfere with infection (Gow and Hube, 2012). In addition, secreted proteins have important functions, such as nutrient supply, cell-to-cell communication, environmental detoxification, killing potential competitors, and aiding survival in the host (Bonin-Debs et al., 2004; Nombela et al., 2006; Holbrook etal., 2011; Weber etal., 2012). One of the main characteristics of pathogenesis is inducing damage to the host, which can occur directly due to the fungus and its virulence factors when it invades deep into or through the host tissues. Damage may also result from over-activation of the immune system through, for example, massive neutrophil infiltration or an inappropriate and unbalanced systemic response, which produces life-threatening sepsis. Thus, immune recognition may not only 


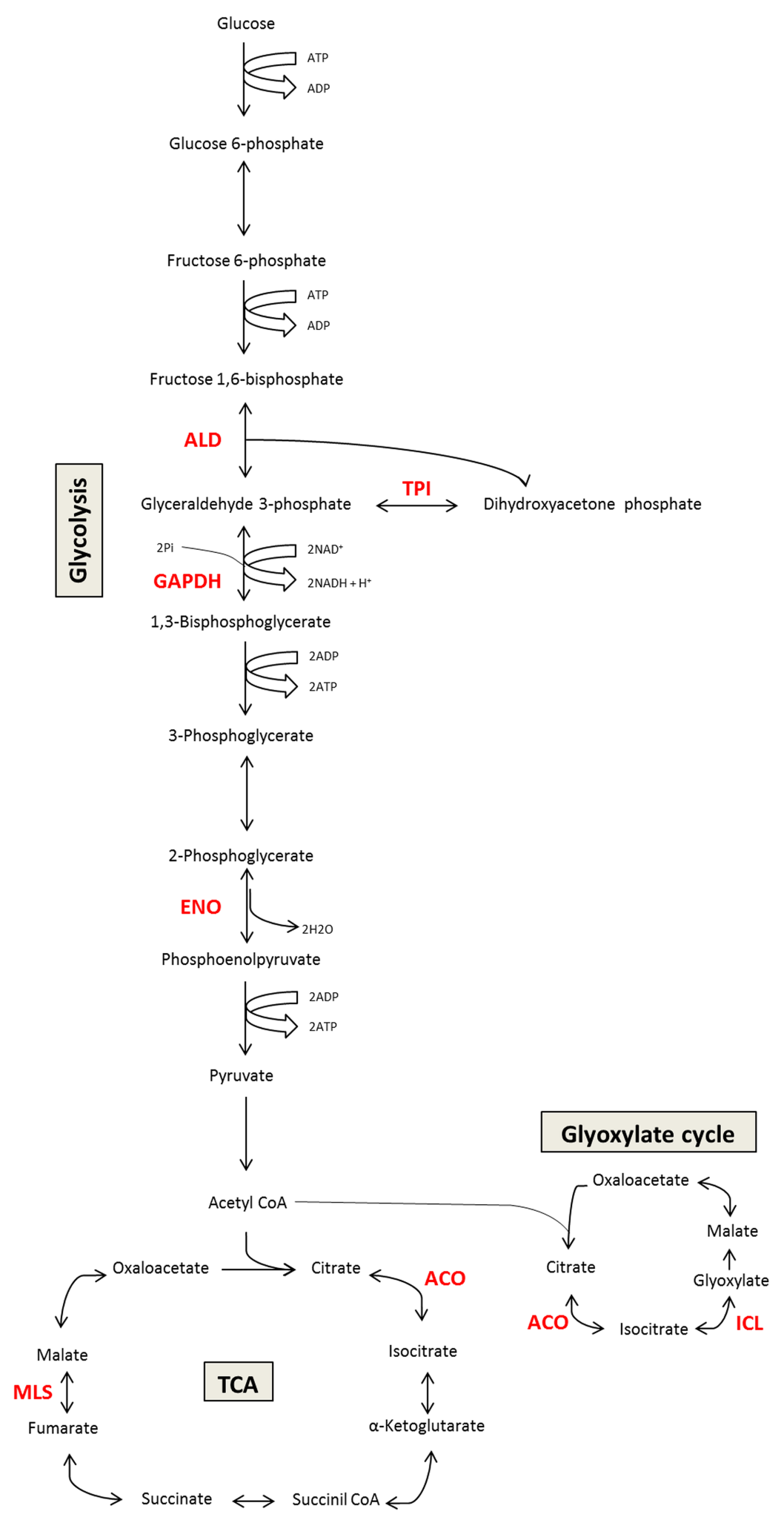

FIGURE 1 | Schematic representation of moonlighting proteins involved in Paracoccidioides spp. carbon metabolism (glycolysis/TCA cycle/ glyoxylate cycle). The figure summarizes the canonical function of the moonlighting proteins that are also involved in Paracoccidioides-host interactions. In red, we highlighted the enzymes with moonlighting functions that have been studied. ALD, aldolase; GAPDH, glyceraldehyde-3-phosphate dehydrogenase; ENO, enolase; MLS, malate synthase; TPI, triose phosphate isomerase; $\mathrm{ACO}$, aconitase; ICL, isocitrate lyase. 
be beneficial and crucial for fighting invading fungi but may also be an integral part of the disease process (Gow and Hube, 2012).

\section{FRUCTOSE 1,6-BISPHOSPHATE ALDOLASE}

Fructose 1,6-bisphosphate aldolase catalyzes reversible cleavage of fructose 1-6, bisphosphate into two triose phosphates, dihydroxyacetone phosphate and glyceraldehyde 3-phosphate. The reaction is common to glycolysis and gluconeogenesis (Marsh and Lebherz, 1992). Paracoccidioides spp. contains two genes that encode different Class II FBAs. FBA gene duplication in Paracoccidioides spp. was supported by phylogenetic analysis and established a twomember family with potentially differing functions. In addition, expression analysis support differential expression of Pbfbal and Pbfba2, which indicates distinct functions for the two proteins (Carneiro et al., 2005). The presence of a paralogous gene supports acquisition of a new function, even if the new function is related to the original function (Tatusov et al., 1997). In Paracoccidioides spp., the Pbfba2 transcript was only detected in mycelial form, whereas the Pbfbal transcript was detected in yeast cells (Chaves, 2013), further suggesting distinct functions.

Interestingly, FBA was detected in the P. lutzii secretome and cell wall during macrophage infection (Chaves, 2013). In proteomic studies on the yeast and mycelial phases, FBA was detected in the cell wall and extracellular vesicles, exclusively in the $P$. brasiliensis yeast-phase (Longo etal., 2014). Data show that the cell surface FBA1 includes immunogenic properties because the native protein can be recognized by serum from patients infected with paracoccidioidomycosis (PCM; da Fonseca et al., 2001). In the Paracoccidioides genus, both FBA isoforms could bind human plasminogen and convert plasminogen into plasmin in the presence of tissue plasminogen activator (tPA), which may increase the fibrinolytic capacity of the fungus, demonstrating that FBA is involved in the adhesion and invasion processes (Chaves, 2013). FBA also seems important in host-fungus interactions (Burucoa et al., 1995; McCarthy et al., 2002; Starnes et al., 2009; Capodagli et al., 2014).

\section{GLYCERALDEHYDE-3-PHOSPHATE DEHYDROGENASE}

Glyceraldehyde 3-phosphate dehydrogenase is a glycolytic enzyme that catalyzes glyceraldehyde 3-phosphate conversion into 1,3bisphosphoglycerate. The most common form in all organisms is the $\mathrm{NAD}^{+}$-dependent enzyme, which is typically located in the cytoplasm (Tunio et al., 2010).

In addition to the intracellular location of GAPDH, it is also present in the most external layer of the cell wall in Paracoccidioides spp. yeast cells at higher quantities than in the cytoplasm. The presence of GAPDH in the cell wall and extracellular vesicles of $P$. brasiliensis during the yeast and mycelium phases was demonstrated using proteomic analysis (Longo et al., 2014), which suggests that it is involved in pathogenesis (Barbosa et al., 2004). The involvement of surface GAPDH in the interaction between Paracoccidioides spp. and laminin, fibronectin, and type I collagen has been demonstrated (Barbosa et al., 2004, 2006). GAPDH binding to laminin, fibronectin, and type I collagen may indicate that it is a virulence factor.

Purified, recombinant GAPDH protein immunological reactivity with 70 human serum samples was tested using Western blot analysis. GAPDH reacted with antibodies in the PCM patient serum, but not in the control patients' sera; thus, GAPDH is included in the arsenal of $P$. brasiliensis immunoreactive molecules (Santos et al., 2012).

The Paracoccidioides spp. GAPDH likely plays a role in the initial phases of fungal infection. A reduced interaction between Paracoccidioides spp. and epithelial cells was demonstrated using recombinant GAPDH protein and the polyclonal anti-GAPDH, which suggests that this protein may be important during the Paracoccidioides spp. infection process (Barbosa et al., 2006).

Bailão etal. (2006) used representational difference analysis (RDA) to identify genes induced during the infection process in experimental animal livers under conditions that mimic hematogenous dissemination of the fungus. The researchers showed that GAPDH was overexpressed during infection, and similar results were observed when $P$. brasiliensis yeast cells were incubated with human blood, which supports the notion that this molecule may be involved in pathogenesis. GAPDH mRNA was also identified in the $P$. brasiliensis transcriptome from mouse liver, which reinforces its potential role in the infection process (Costa et al., 2007).

In a study on the $P$. brasiliensis transcription response upon internalization by macrophages, GAPDH was down-regulated, which suggests a complex carbon-depleted environment in the macrophage that yields a similar adaptive response as in intracellular fungal pathogens (Tavares et al., 2007).

All of the data suggest that GAPDH includes adhesin characteristics and plays an important role in the fungus-host interaction, which triggers host cell processes involved in pathogenesis.

\section{TRIOSE PHOSPHATE ISOMERASE (TPI)}

Triose phosphate isomerase (TPI) is an enzyme that rapidly interconverts dihydroxyacetone phosphate and D-glyceraldehyde 3-phosphate in the glycolysis pathway (Wierenga et al., 2010). The Paracoccidioides spp. TPI was first identified by da Fonseca etal. (2001) through fractionating fungus extracts using two-dimensional electrophoresis and subsequent immunoblotting. Using a strategy to identify Paracoccidioides spp. proteins that react with PCM patient sera, TPI was characterized as an important immunogenic molecule (Pereira et al., 2004). TPI was identified in the cell wall and extracellular vesicles using liquid chromatography coupled with high-resolution massspectrometry (LC-MS/MS) in the yeast and mycelium forms of two different $P$. brasiliensis isolates, $\mathrm{Pb} 18$ and $\mathrm{Pb} 03$ (Longo et al., 2014).

Additionally, TPI expression is developmentally regulated in Paracoccidioides spp.; expression increases when the fungus adopts the pathogenic yeast-like morphology. TPI also plays a role in the fungus-host interaction because the recombinant protein interacts with pneumocytes through binding the ECM components laminin and fibronectin. Finally, P. brasiliensis pre-treatment with a TPI polyclonal antibody inhibits adhesion to pneumocytes (Pereira et al., 2007).

\section{ENOLASE}

Enolase is also referred to as phosphopyruvate hydratase and is one of the most abundantly expressed cytosolic proteins 
in many organisms. It is a key glycolytic enzyme that catalyzes 2-phosphoglycerate dehydration to phosphoenolpyruvate (Pancholi, 2001). ENO was identified in the cell wall and extracellular vesicles in both the P. brasiliensis mycelium and yeast phases; it is secreted from unconventional pathways, which was predicted using the Fungal Secretome Database (Longo et al., 2014). Unconventional extracellular export pathways include plasma membrane transporter actions and the use of vesicles that originate from the plasma membrane, lysosomal secretion, or exosome release (Nickel, 2010; Rodrigues et al., 2011).

The capacity to bind to plasminogen and fibronectin as well as superficial localization have been linked to the pathogenic role of ENO in Paracoccidioides spp. (Donofrio et al., 2009; Nogueira etal., 2010; Marcos etal., 2012). Certain non-glycolytic ENO properties described above, particularly the properties related to surface expression and plasminogen binding, indicate that ENO may play an important role in initiating the infection process through modulating the pericellular and intravascular fibrinolytic system. Additionally, the internal ${ }_{254} \mathrm{FYKADEKK}_{262}$ motif may be responsible for plasminogen binding, especially through the C-terminal lysine. $P$. brasiliensis ENO also includes an RGD motif (Arg-Gly-Asp), which is a sequence motif that mediates cell attachment. Marcos et al. (2012) demonstrated that ENO attachment to pneumocytes was inhibited, which suggests that the RGD peptide competes with the ENO binding site in pneumocytes.

Nogueira et al. (2010) demonstrated that treating epithelial cells and phagocytes with recombinant $P$. brasiliensis ENO ( $\mathrm{rPbEno}$ ) increases the effectiveness of the Paracoccidioides spp. interaction with host components because rPbEno enhances the exposure of surface $N$-acetylglucosamine residues, which Paracoccidioides spp. uses as a surface site for adherence to host cells (Coltri et al., 2006; Ganiko et al., 2007; Donofrio et al., 2009; dos Reis Almeida et al., 2010).

These data indicate that the Paracoccidioides spp. ENO may also have different subcellular locations (i.e., the cytoplasm or cell wall). Further, ENO has other functions in addition to its metabolic role that contributes to the virulence of this fungus.

\section{MALATE SYNTHASE}

The glyoxylate cycle is a TCA cycle anaplerotic pathway that facilitates growth on $\mathrm{C}$ (2) compounds through bypassing the $\mathrm{CO}$ (2)-generating TCA cycle steps. MLS converts glyoxylate and acetyl-CoA to malate (Dunn et al., 2009).

In Paracoccidioides spp., MLS participates in the glyoxylate cycle and allantoin degradation, which allows the cell to use purine as a nitrogen source (Zambuzzi-Carvalho et al., 2009); MLS is likely important for infection because its transcript is up-regulated during the mycelium to yeast transition, during the infectious phase (Bastos et al., 2007), and, in yeast cells, during phagocytosis by murine macrophages (Derengowski et al., 2008). da Silva Neto et al. (2009) showed that the Paracoccidioides spp. MLS is located on the cell surface and binds certain ECM components, such as type I and IV collagens, fibronectin and pneumocytes. AntiMLS Paracoccidioides spp. antibodies inhibit the interaction with epithelial cells in vitro, which suggests that this protein contributes to adhesion between the fungus and host tissues.

\section{ISOCITRATE LYASE}

Isocitrate lyase is a glyoxylate cycle enzyme that converts isocitrate to glyoxylate and succinate; it is important for maintaining the TCA cycle afforded by the glyoxylate cycle when pyruvate generation from glycolysis is lower and fatty acid $\beta$-oxidation provides the major carbon source (Gould et al., 2006).

Isocitrate lyase protein was observed in the Paracoccidioides spp. culture filtrate; it is actively secreted to the Paracoccidioides spp. cell surface (Cruz et al., 2011). Troian (2009) demonstrated that recombinant ICL from $P$. brasiliensis (PbICL) and its polyclonal antibody inhibited interactions between $P$. brasiliensis and epithelial cells, which suggest a role in adhesion to host tissue. Cruz et al. (2011) reported that recombinant ICL binds fibronectin and type IV collagen, which reinforces the importance of this protein during the Paracoccidioides-host interaction.

Isocitrate lyase transcripts from Paracoccidioides spp. are induced during the yeast phase, during infection in a murine model (Felipe etal., 2005; Costa etal., 2007), and during the mycelium to yeast transition (Goldman et al., 2003; Bastos et al., 2007). Additionally, the gene that encodes ICL was induced during the fungus-macrophage interaction upon carbon starvation (Lima et al., 2014).

Argentilactone, which is a natural constituent of essential oil from Hyptis avalifolia, and its semi-synthetic derivate inhibited ICL activity in the presence of acetate, which affects $P$. lutzii yeast growth and mycelium to yeast differentiation (Prado et al., 2014). This finding suggests a significant role for Paracoccidioides spp. ICL in the host-pathogen interaction because the transition to the yeast phase of the fungus is essential for establishing infection and disease (San-Blas et al., 2002; Santana et al., 2012). Considering that pathogenic microorganisms utilize different carbon sources during pathogenesis (Barelle et al., 2006) and considering that PbICL is regulated by carbon sources (Prado et al., 2014), it is notable that ICL inhibition can affect cell growth and differentiation due a change in the carbon source used by the pathogen.

These studies indicate an adhesin behavior for Paracoccidioides spp. ICL and that it plays an important role in adhesion and colonization of this fungus in host tissue.

\section{ACONITASE}

Aconitase catalyzes the second step of the TCA cycle, which includes stereo-specific isomerization of citrate to isocitrate via cis-aconitate. In addition to its role in energy generation, the TCA cycle generates essential precursors for amino acid, fatty acid, and carbohydrate biosynthesis (da Fonseca et al., 2001).

Brito etal. (2011) used Western blot and immunocytochemistry analysis to demonstrate $P$. brasiliensis ACO (PbACO) in the extracellular fluid and that is associated with the cell wall, mitochondria, cytosol, and peroxisomes in yeast cells. Additionally, the researchers observed that $\mathrm{PbACO}$ was overexpressed when the cells were grown with ethanol and acetate as carbon sources and at higher iron levels, which suggests a potential role for PbACO in iron metabolism.

\section{FINAL STATEMENTS}

Studies on bacterial and fungal moonlighting proteins are in an early stage. One startling discovery demonstrated that the majority 
of proteins in the bacterial glycolytic pathway have certain adhesive functions (Henderson and Martin, 2011), which was also observed in Paracoccidioides spp. In this review, we collect the results for moonlighting enzyme activities in the glycolytic pathway as well as in the TCA and glyoxylate cycles, which have been described as ECM ligands in Paracoccidioides spp. In addition to adding to the number and types of known moonlighting proteins, these new examples also add to current information on the general importance of moonlighting proteins (Chung et al., 1999; Jeffery, 1999, 2003a, 2009).

Based on all of the data, the Paracoccidioides spp. moonlighting proteins include different functions in addition to their conventional metabolism roles due to their surface location. Clearly, moonlighting, or the ability to perform biological functions unrelated to the canonical function assigned to the protein, is common in fungal proteins in addition to bacteria (Kainulainen and Korhonen, 2014). A general conclusion is that moonlighting proteins seem to communicate with the environment and in response to environmental changes or stress. The moonlighting proteins present on the cell surface of Paracoccidioides species and released through vesicles are thought to function in host interactions. The specific roles of most cell surface proteins remain unclear, but a few such proteins are involved in cell wall biosynthesis/remodeling, adaptation to different environmental conditions, and PCM pathogenesis. Thus, moonlighting proteins may be potential targets for designing drugs against systemic mycosis.

\section{REFERENCES}

Aharoni, A., Gaidukov, L., Khersonsky, O., Mcq Gould, S., Roodveldt, C., and Tawfik, D. S. (2005). The 'evolvability' of promiscuous protein functions. Nat. Genet. 37, 73-76.

Albring, M., Griffith, J., and Attardi, G. (1977). Association of a protein structure of probable membrane derivation with HeLa cell mitochondrial DNA near its origin of replication. Proc. Natl. Acad. Sci. U.S.A. 74, 1348-1352. doi: 10.1073/pnas.74.4.1348

Andreotti, P. F., Monteiro Da Silva, J. L., Bailão, A. M., Soares, C. M., Benard, G., Soares, C. P., et al. (2005). Isolation and partial characterization of a 30 $\mathrm{kDa}$ adhesin from Paracoccidioides brasiliensis. Microbes Infect. 7, 875-881. doi: 10.1016/j.micinf.2005.02.005

Angiolella, L., Facchin, M., Stringaro, A., Maras, B., Simonetti, N., and Cassone, A. (1996). Identification of a glucan-associated enolase as a main cell wall protein of Candida albicans and an indirect target of lipopeptide antimycotics. J. Infect. Dis. 173, 684-690. doi: 10.1093/infdis/173.3.684

Bailão, A. M., Schrank, A., Borges, C. L., Dutra, V., Walquíria Inês Molinari-Madlum, E. E., Soares Felipe, M. S., et al. (2006). Differential gene expression by Paracoccidioides brasiliensis in host interaction conditions: representational difference analysis identifies candidate genes associated with fungal pathogenesis. Microbes Infect. 8, 2686-2697. doi: 10.1016/j.micinf.2006.07.019

Baker, H. V. (1991). GCR1 of Saccharomyces cerevisiae encodes a DNA binding protein whose binding is abolished by mutations in the CTTCC sequence motif. Proc. Natl. Acad. Sci. U.S.A. 88, 9443-9447. doi: 10.1073/pnas.88. 21.9443

Barbosa, M. S., Báo, S. N., Andreotti, P. F., De Faria, F. P., Felipe, M. S., Dos Santos Feitosa, L., et al. (2006). Glyceraldehyde-3-phosphate dehydrogenase of Paracoccidioides brasiliensis is a cell surface protein involved in fungal adhesion to extracellular matrix proteins and interaction with cells. Infect. Immun. 74, 382-389. doi: 10.1128/IAI.74.1.382-389.2006

Barbosa, M. S., Cunha Passos, D. A., Felipe, M. S., Jesuíno, R. S., Pereira, M., and De Almeida Soares, C. M. (2004). The glyceraldehyde-3-phosphate dehydrogenase homologue is differentially regulated in phases of Paracoccidioides brasiliensis: molecular and phylogenetic analysis. Fungal Genet. Biol. 41, 667-675. doi: 10.1016/j.fgb.2004.02.002
Barelle, C. J., Priest, C. L., Maccallum, D. M., Gow, N. A. R., Odds, F. C., and Brown, A. J. P. (2006). Niche-specific regulation of central metabolic pathways in a fungal pathogen. Cell. Microbiol. 8, 961-971. doi: 10.1111/j.1462-5822.2005. 00676.x

Bastos, K. P., Bailão, A. M., Borges, C. L., Faria, F. P., Felipe, M. S., Silva, M. G., et al. (2007). The transcriptome analysis of early morphogenesis in Paracoccidioides brasiliensis mycelium reveals novel and induced genes potentially associated to the dimorphic process. BMC Microbiol. 7:29. doi: 10.1186/1471-2180-7-29

Bonin-Debs, A. L., Boche, I., Gille, H., and Brinkmann, U. (2004). Development of secreted proteins as biotherapeutic agents. Expert Opin. Biol. Ther. 4, 551-558. doi: $10.1517 / 14712598.4 .4 .551$

Brilli, M., and Fani, R. (2004). The origin and evolution of eucaryal HIS7 genes: from metabolon to bifunctional proteins? Gene 339, 149-160. doi: 10.1016/j.gene.2004.06.033

Brito, W. E. A., Rezende, T. C., Parente, A. F., Ricart, C. A., Sousa, M. V., Báo, S. N., et al. (2011). Identification, characterization and regulation studies of the aconitase of Paracoccidioides brasiliensis. Fungal Biol. 115, 697-707. doi: 10.1016/j.funbio.2011.02.011

Burucoa, C., Frémaux, C., Pei, Z., Tummuru, M., Blaser, M. J., Cenatiempo, Y., et al. (1995). Nucleotide sequence and characterization of peb4A encoding an antigenic protein in Campylobacter jejuni. Res. Microbiol. 146, 467-476. doi: 10.1016/0923-2508(96)80292-0

Capodagli, G. C., Sedhom, W. G., Jackson, M., Ahrendt, K. A., and Pegan, S. D. (2014). A noncompetitive inhibitor for Mycobacterium tuberculosis's class IIa fructose 1,6-bisphosphate aldolase. Biochemistry 53, 202-213. doi: 10.1021/bi401022b

Carneiro, L. C., De Faria, F. P., Felipe, M. S., Pereira, M., and De Almeida Soares, C. M. (2005). Paracoccidioides brasiliensis presents two different cDNAs encoding homologues of the fructose 1,6-biphosphate aldolase: protein isolation, cloning of the cDNAs and genes, structural, phylogenetic, and expression analysis. Fungal Genet. Biol. 42, 51-60. doi: 10.1016/j.fgb.2004.10.003

Chaves, E. G. A. (2013). Identificação e Análise de Proteínas Ligantes de Plasminogênio de Paracoccidioides. Master, Universidade Federal de Goiás, Goiás.

Chen, X., Wang, X., Kaufman, B., and Butow, R. (2005). Aconitase couples metabolic regulation to mitochondrial DNA maintenance. Science 307, 714-717. doi: $10.1126 /$ science.1106391

Chung, S., Mclean, M. R., and Rymond, B. C. (1999). Yeast ortholog of the Drosophila crooked neck protein promotes spliceosome assembly through stable U4/U6.U5 snRNP addition. RNA 5, 1042-1054. doi: 10.1017/S1355838299990635

Clarke, J. L., Scopes, D. A., Sodeinde, O., and Mason, P. J. (2001). Glucose6-phosphate dehydrogenase-6-phosphogluconolactonase. A novel bifunctional enzyme in malaria parasites. Eur. J. Biochem. 268, 2013-2019. doi: 10.1046/j.14321327.2001.02078.x

Coltri, K. C., Casabona-Fortunato, A. S., Gennari-Cardoso, M. L., Pinzan, C. F., Ruas, L. P., Mariano, V. S., et al. (2006). Paracoccin, a GlcNAc-binding lectin from Paracoccidioides brasiliensis, binds to laminin and induces TNF-alpha production by macrophages. Microbes Infect. 8, 704-713. doi: 10.1016/j.micinf.2005. 09.008

Commichau, F. M., Rothe, F. M., Herzberg, C., Wagner, E., Hellwig, D., LehnikHabrink, M., et al. (2009). Novel activities of glycolytic enzymes in Bacillus subtilis: interactions with essential proteins involved in mRNA processing. Mol. Cell. Proteom. 8, 1350-1360. doi: 10.1074/mcp.M800546-MCP200

Copley, S. D. (2012). Moonlighting is mainstream: paradigm adjustment required. Bioessays 34, 578-588. doi: 10.1002/bies.201100191

Costa, M., Borges, C. L., Bailão, A. M., Meirelles, G. V., Mendonça, Y. A., Dantas, S. F., et al. (2007). Transcriptome profiling of Paracoccidioides brasiliensis yeastphase cells recovered from infected mice brings new insights into fungal response upon host interaction. Microbiology 153, 4194-4207. doi: 10.1099/mic.0.2007/ 009332-0

Crowe, J. D., Sievwright, I. K., Auld, G. C., Moore, N. R., Gow, N. A., and Booth, N. A. (2003). Candida albicans binds human plasminogen: identification of eight plasminogen-binding proteins. Mol. Microbiol. 47, 1637-1651. doi: 10.1046/j.1365-2958.2003.03390.x

Cruz, A. H., Brock, M., Zambuzzi-Carvalho, P. F., Santos-Silva, L. K., Troian, R. F., Góes, A. M., et al. (2011). Phosphorylation is the major mechanism regulating isocitrate lyase activity in Paracoccidioides brasiliensis yeast cells. FEBS J. 278, 2318-2332. doi: 10.1111/j.1742-4658.2011.08150.x

da Fonseca, C. A., Jesuino, R. S., Felipe, M. S., Cunha, D. A., Brito, W. A., and Soares, C. M. (2001). Two-dimensional electrophoresis and characterization of antigens 
from Paracoccidioides brasiliensis. Microbes Infect. 3, 535-542. doi: 10.1016/S12864579(01)01409-5

da Silva Neto, B. R., De Fátima Da Silva, J., Mendes-Giannini, M. J., Lenzi, H. L., De Almeida Soares, C. M., and Pereira, M. (2009). The malate synthase of Paracoccidioides brasiliensis is a linked surface protein that behaves as anchorless adhesin. BMC Microbiol. 9:272. doi: 10.1186/1471-2180-9-272

Decker, B. L., and Wickner, W. T. (2006). Enolase activates homotypic vacuole fusion and protein transport to the vacuole in yeast. J. Biol. Chem. 281, 14523-14528. doi: 10.1074/jbc.M600911200

Delgado, M. L., Gil, M. L., and Gozalbo, D. (2003). Candida albicans TDH3 gene promotes secretion of internal invertase when expressed in Saccharomyces cerevisiae as a glyceraldehyde-3-phosphate dehydrogenase-invertase fusion protein. Yeast 20, 713-722. doi: 10.1002/yea.993

Derengowski, L. S., Tavares, A. H., Silva, S., Procópio, L. S., Felipe, M. S., and SilvaPereira, I. (2008). Upregulation of glyoxylate cycle genes upon Paracoccidioides brasiliensis internalization by murine macrophages and in vitro nutritional stress condition. Med. Mycol. 46, 125-134. doi: 10.1080/13693780701670509

Donofrio, F. C., Calil, A. C., Miranda, E. T., Almeida, A. M., Benard, G., Soares, C. P., et al. (2009). Enolase from Paracoccidioides brasiliensis: isolation and identification as a fibronectin-binding protein. J. Med. Microbiol. 58, 706-713. doi: 10.1099/jmm.0.003830-0

dos Reis Almeida, F. B., De Oliveira, L. L., Valle De Sousa, M., Barreira, M. C., and Hanna, E. S. (2010). Paracoccin from Paracoccidioides brasiliensis; purification through affinity with chitin and identification of $\mathrm{N}$-acetyl-beta-Dglucosaminidase activity. Yeast 27,67-76. doi: 10.1002/yea.1731

Dunn, M. F., Ramírez-Trujillo, J. A., and Hernández-Lucas, I. (2009). Major roles of isocitrate lyase and malate synthase in bacterial and fungal pathogenesis. Microbiology 155, 3166-3175. doi: 10.1099/mic.0.030858-0

Ebel, F., Schwienbacher, M., Beyer, J., Heesemann, J., Brakhage, A. A., and Brock, M. (2006). Analysis of the regulation, expression, and localisation of the isocitrate lyase from Aspergillus fumigatus, a potential target for antifungal drug development. Fungal Genet. Biol. 43, 476-489. doi: 10.1016/j.fgb.2006.01.015

Eroles, P., Sentandreu, M., Elorza, M. V., and Sentandreu, R. (1997). The highly immunogenic enolase and Hsp70p are adventitious Candida albicans cell wall proteins. Microbiology 143, 313-320. doi: 10.1099/00221287-143-2-313

Felipe, M. S., Andrade, R. V., Arraes, F. B., Nicola, A. M., Maranhão, A. Q., Torres, F. A., et al. (2005). Transcriptional profiles of the human pathogenic fungus Paracoccidioides brasiliensis in mycelium and yeast cells. J. Biol. Chem. 280, 2470624714. doi: 10.1074/jbc.M500625200

Fothergill-Gilmore, L. A., and Michels, P. A. (1993). Evolution of glycolysis. Prog. Biophys. Mol. Biol. 59, 105-235. doi: 10.1016/0079-6107(93)90001-Z

Fox, D., and Smulian, A. G. (2001). Plasminogen-binding activity of enolase in the opportunistic pathogen Pneumocystis carinii. Med. Mycol. 39, 495-507. doi: 10.1080/mmy.39.6.495.507

Gainey, L. D., Connerton, I. F., Lewis, E. H., Turner, G., and Ballance, D. J. (1992). Characterization of the glyoxysomal isocitrate lyase genes of Aspergillus nidulans (acuD) and Neurospora crassa (acu-3). Curr. Genet. 21, 43-47. doi: 10.1007/BF00318653

Gancedo, C., and Flores, C. L. (2008). Moonlighting proteins in yeasts. Microbiol. Mol. Biol. Rev. 72, 197-210. doi: 10.1128/MMBR.00036-07

Ganiko, L., Puccia, R., Mariano, V. S., Sant'anna, O. A., Freymüller, E., RoqueBarreira, M. C., et al. (2007). Paracoccin, an N-acetyl-glucosamine-binding lectin of Paracoccidioides brasiliensis, is involved in fungal growth. Microbes Infect. 9 , 695-703. doi: 10.1016/j.micinf.2007.02.012

Gil-Navarro, I., Gil, M. L., Casanova, M., O’Connor, J. E., Martínez, J. P., and Gozalbo, D. (1997). The glycolytic enzyme glyceraldehyde-3-phosphate dehydrogenase of Candida albicans is a surface antigen. J. Bacteriol. 179, 4992-4999.

Goldman, G. H., Dos Reis Marques, E., Duarte Ribeiro, D. C., De Souza Bernardes, L. A., Quiapin, A. C., Vitorelli, P. M., et al. (2003). Expressed sequence tag analysis of the human pathogen Paracoccidioides brasiliensis yeast phase: identification of putative homologues of Candida albicans virulence and pathogenicity genes. Eukaryot. Cell 2, 34-48. doi: 10.1128/EC.2.1.34-48.2003

Gómez, A., Hernández, S., Amela, I., Piñol, J., Cedano, J., and Querol, E. (2011). Do protein-protein interaction databases identify moonlighting proteins? Mol. Biosyst. 7, 2379-2382. doi: 10.1039/clmb05180f

González, A., Gómez, B. L., Diez, S., Hernández, O., Restrepo, A., Hamilton, A. J., et al. (2005). Purification and partial characterization of a Paracoccidioides brasiliensis protein with capacity to bind to extracellular matrix proteins. Infect. Immun. 73, 2486-2495. doi: 10.1128/IAI.73.4.2486-2495.2005

Gould, T. A., Van De Langemheen, H., Muñoz-Elías, E. J., Mckinney, J. D., and Sacchettini, J. C. (2006). Dual role of isocitrate lyase 1 in the glyoxylate and methylcitrate cycles in Mycobacterium tuberculosis. Mol. Microbiol. 61, 940-947. doi: 10.1111/j.1365-2958.2006.05297.x

Gow, N. A. R., and Hube, B. (2012). Importance of the Candida albicans cell wall during commensalism and infection. Curr. Opin. Microbiol. 15, 406-412. doi: 10.1016/j.mib.2012.04.005

Hanna, S. A., Monteiro Da Silva, J. L., and Giannini, M. J. (2000). Adherence and intracellular parasitism of Paracoccidioides brasiliensis in Vero cells. Microbes Infect. 2, 877-884. doi: 10.1016/S1286-4579(00)00390-7

Henderson, B., and Martin, A. (2011). Bacterial virulence in the moonlight: multitasking bacterial moonlighting proteins are virulence determinants in infectious disease. Infect. Immun. 79, 3476-3491. doi: 10.1128/IAI.00179-11

Hendriks, W., Mulders, J. W., Bibby, M. A., Slingsby, C., Bloemendal, H., and De Jong, W. W. (1988). Duck lens epsilon-crystallin and lactate dehydrogenase B4 are identical: a single-copy gene product with two distinct functions. Proc. Natl. Acad. Sci. U.S.A. 85, 7114-7118. doi: 10.1073/pnas.85.19.7114

Holbrook, E. D., Edwards, J. A., Youseff, B. H., and Rappleye, C. A. (2011). Definition of the extracellular proteome of pathogenic-phase Histoplasma capsulatum. J. Proteome Res. 10, 1929-1943. doi: 10.1021/pr1011697

Huberts, D. H., and van der Klei, I. J. (2010). Moonlighting proteins: an intriguing mode of multitasking. Biochim. Biophys. Acta 1803, 520-525. doi: 10.1016/j.bbamcr.2010.01.022

James, C. L., and Viola, R. E. (2002). Production and characterization of bifunctional enzymes. Substrate channeling in the aspartate pathway. Biochemistry 41, 37263731. doi: 10.1021/bi0159074

Jeffery, C. J. (1999). Moonlighting proteins. Trends Biochem. Sci. 24, 8-11. doi: 10.1016/S0968-0004(98)01335-8

Jeffery, C. J. (2003a). Moonlighting proteins: old proteins learning new tricks. Trends Genet. 19, 415-417. doi: 10.1016/S0168-9525(03)00167-7

Jeffery, C. J. (2003b). Multifunctional proteins: examples of gene sharing. Ann. Med. 35, 28-35. doi: 10.1080/07853890310004101

Jeffery, C. J. (2004). Molecular mechanisms for multitasking: recent crystal structures of moonlighting proteins. Curr. Opin. Struct. Biol. 14, 663-668. doi: 10.1016/j.sbi.2004.10.001

Jeffery, C. J. (2009). Moonlighting proteins-an update. Mol. Biosyst. 5, 345-350. doi: 10.1039/b900658n

Jong, A. Y., Chen, S. H., Stins, M. F., Kim, K. S., Tuan, T. L., and Huang, S. H. (2003). Binding of Candida albicans enolase to plasmin(ogen) results in enhanced invasion of human brain microvascular endothelial cells. J. Med. Microbiol. 52, 615-622. doi: 10.1099/jmm.0.05060-0

Kainulainen, V., and Korhonen, T. K. (2014). Dancing to another tune-adhesive moonlighting proteins in bacteria. Biology 3, 178-204. doi: 10.3390/biology3010178

Kelkar, Y. D., and Ochman, H. (2013). Genome reduction promotes increase in protein functional complexity in bacteria. Genetics 193, 303-307. doi: 10.1534/genetics.112.145656

Keller, S., Sanderson, M. P., Stoeck, A., and Altevogt, P. (2006). Exosomes: from biogenesis and secretion to biological function. Immunol. Lett. 107, 102-108. doi: 10.1016/j.imlet.2006.09.005

Kim, J. W., and Dang, C. V. (2005). Multifaceted roles of glycolytic enzymes. Trends Biochem. Sci. 30, 142-150. doi: 10.1016/j.tibs.2005.01.005

Kirschner, K., and Bisswanger, H. (1976). Multifunctional proteins. Annu. Rev. Biochem. 45, 143-166. doi: 10.1146/annurev.bi.45.070176.001043

Lima, P. E. S., Casaletti, L., Bailão, A. M., De Vasconcelos, A. T., Fernandes, G. A. R., and Soares, C. M. (2014). Transcriptional and proteomic responses to carbon starvation in Paracoccidioides. PLoS Negl. Trop. Dis. 8:e2855. doi: 10.1371/journal.pntd.0002855

Longo, L. V. G., Da Cunha, J. P. C., Sobreira, T. J. P., and Puccia, R. (2014). Proteome of cell wall-extracts from pathogenic Paracoccidioides brasiliensis: comparison among morphological phases, isolates, and reported fungal extracellular vesicle proteins. EuPA Open Proteom. 3, 216-228. doi: 10.1016/j.euprot.2014.03.003

Lu, M., Ammar, D., Ives, H., Albrecht, F., and Gluck, S. L. (2007). Physical interaction between aldolase and vacuolar $\mathrm{H}^{+}$-ATPase is essential for the assembly and activity of the proton pump. J. Biol. Chem. 282, 24495-24503. doi: 10.1074/jbc.M702598200 
Lu, M., Holliday, L. S., Zhang, L., Dunn, W. A. Jr., and Gluck, S. L. (2001). Interaction between aldolase and vacuolar $\mathrm{H}^{+}$-ATPase: evidence for direct coupling of glycolysis to the ATP-hydrolyzing proton pump. J. Biol. Chem. 276, 30407-30413. doi: 10.1074/jbc.M008768200

Marcos, C. M., De Fátima Da Silva, J., De Oliveira, H. C., Moraes Da Silva, R. A., Mendes-Giannini, M. J., and Fusco-Almeida, A. M. (2012). Surface-expressed enolase contributes to the adhesion of Paracoccidioides brasiliensis to host cells. FEMS Yeast Res. 12, 557-570. doi: 10.1111/j.1567-1364.2012.00806.x

Marsh, J. J., and Lebherz, H. G. (1992). Fructose-bisphosphate aldolases: an evolutionary history. Trends Biochem. Sci. 17, 110-113. doi: 10.1016/09680004(92)90247-7

McCarthy, J. S., Wieseman, M., Tropea, J., Kaslow, D., Abraham, D., Lustigman, S., et al. (2002). Onchocerca volvulus glycolytic enzyme fructose-1,6-bisphosphate aldolase as a target for a protective immune response in humans. Infect. Immun. 70, 851-858. doi: 10.1128/IAI.70.2.851-858.2002

Mendes-Giannini, M. J., Andreotti, P. F., Vincenzi, L. R., Da Silva, J. L. Lenzi, H. L., Benard, G., et al. (2006). Binding of extracellular matrix proteins to Paracoccidioides brasiliensis. Microbes Infect. 8, 1550-1559. doi: 10.1016/j.micinf.2006.01.012

Mendes-Giannini, M. J., Monteiro Da Silva, J. L., De Fátima Da Silva, J., Donofrio, F. C., Miranda, E. T., Andreotti, P. F., et al. (2008). Interactions of Paracoccidioides brasiliensis with host cells: recent advances. Mycopathologia 165, 237-248. doi: 10.1007/s11046-007-9074-z

Moore, B. (2004). Bifunctional and moonlighting enzymes: lighting the way to regulatory control. Trends Plant Sci. 9, 221-228. doi: 10.1016/j.tplants.2004 03.005

Myers, M. G. Jr. (2009). Cell biology. Moonlighting in mitochondria. Science 323, 723-724. doi: 10.1126/science. 1169660

Narahari, J., Ma, R., Wang, M., and Walden, W. E. (2000). The aconitase function of iron regulatory protein 1 . Genetic studies in yeast implicate its role in iron-mediated redox regulation. J. Biol. Chem. 275, 16227-16234. doi: 10.1074/jbc.M910450199

Nickel, W. (2010). Pathways of unconventional protein secretion. Curr. Opin. Biotechnol. 21, 621-626. doi: 10.1016/j.copbio.2010.06.004

Nogueira, S. V., Fonseca, F. L., Rodrigues, M. L., Mundodi, V., Abi-Chacra, E. A., Winters, M. S., et al. (2010). Paracoccidioides brasiliensis enolase is a surface protein that binds plasminogen and mediates interaction of yeast forms with host cells. Infect. Immun. 78, 4040-4050. doi: 10.1128/IAI.00221-10

Nombela, C., Gil, C., and Chaffin, W. L. (2006). Non-conventional protein secretion in yeast. Trends Microbiol. 14, 15-21. doi: 10.1016/j.tim.2005.11.009

Nosanchuk, J. D., Nimrichter, L., Casadevall, A., and Rodrigues, M. L. (2008). A role for vesicular transport of macromolecules across cell walls in fungal pathogenesis. Commun. Integr. Biol. 1, 37-39. doi: 10.4161/cib.1.1.6639

Oliveira, D. L., Nakayasu, E. S., Joffe, L. S., Guimarães, A. J., Sobreira, T. J., Nosanchuk, J. D., et al. (2010). Biogenesis of extracellular vesicles in yeast: many questions with few answers. Commun. Integr. Biol. 3, 533-535. doi 10.4161/cib.3.6.12756

Orita, I., Yurimoto, H., Hirai, R., Kawarabayasi, Y., Sakai, Y., and Kato, N. (2005). The archaeon Pyrococcus horikoshii possesses a bifunctional enzyme for formaldehyde fixation via the ribulose monophosphate pathway. J. Bacteriol. 187, 3636-3642. doi: 10.1128/JB.187.11.3636-3642.2005

Pancholi, V. (2001). Multifunctional alpha-enolase: its role in diseases. Cell. Mol. Life Sci. 58, 902-920. doi: 10.1007/PL00000910

Pancholi, V., and Chhatwal, G. S. (2003). Housekeeping enzymes as virulence factors for pathogens. Int. J. Med. Microbiol. 293, 391-401. doi: 10.1078/1438-422100283

Pancholi, V., and Fischetti, V. A. (1992). A major surface protein on group A streptococci is a glyceraldehyde-3-phosphate-dehydrogenase with multiple binding activity. J. Exp. Med. 176, 415-426. doi: 10.1084/jem.176.2.415

Pandini, A., Fornili, A., Fraternali, F., and Kleinjung, J. (2012). Detection of allosteric signal transmission by information-theoretic analysis of protein dynamics. FASEB J. 26, 868-881. doi: 10.1096/fj.11-190868

Pereira, L. A., Báo, S. N., Barbosa, M. S., Da Silva, J. L., Felipe, M. S., De Santana, J. M., et al. (2007). Analysis of the Paracoccidioides brasiliensis triosephosphate isomerase suggests the potential for adhesin function. FEMS Yeast Res. 7, 13811388. doi: 10.1111/j.1567-1364.2007.00292.x

Pereira, L. A., Pereira, M., Felipe, M. S., Zancopé-Oliveira, R. M., and Soares, C. M. (2004). Proteomic identification, nucleotide sequence, heterologous expression and immunological reactivity of the triosephosphate isomerase of Paracoccidioides brasiliensis. Microbes Infect. 6, 892-900. doi: 10.1016/j.micinf.2004. 05.001

Pitarch, A., Sánchez, M., Nombela, C., and Gil, C. (2002). Sequential fractionation and two-dimensional gel analysis unravels the complexity of the dimorphic fungus Candida albicans cell wall proteome. Mol. Cell. Proteomics 1, 967-982. doi: 10.1074/mcp.M200062-MCP200

Prado, R. S., Alves, R. J., Oliveira, C. M., Kato, L., Silva, R. A., Quintino, G. O., et al. (2014). Inhibition of Paracoccidioides lutzii $\mathrm{Pb} 01$ isocitrate lyase by the natural compound argentilactone and its semi-synthetic derivatives. PLoS ONE 9:e94832. doi: 10.1371/journal.pone.0094832.g001

Rodrigues, M. L., Nakayasu, E. S., Almeida, I. C., and Nimrichter, L. (2014). The impact of proteomics on the understanding of functions and biogenesis of fungal extracellular vesicles. J. Proteom. 97, 177-186. doi: 10.1016/j.jprot.2013.04.001

Rodrigues, M. L., Nosanchuk, J. D., Schrank, A., Vainstein, M. H., Casadevall, A., and Nimrichter, L. (2011). Vesicular transport systems in fungi. Future Microbiol. 6, 1371-1381. doi: 10.2217/fmb.11.112

Rouault, T. A., Stout, C. D., Kaptain, S., Harford, J. B., and Klausner, R. D. (1991). Structural relationship between an iron-regulated RNA-binding protein (IRE-BP) and aconitase: functional implications. Cell 64, 881-883. doi: 10.1016/0092-8674(91)90312-M

San-Blas, G., Niño-Vega, G., and Iturriaga, T. (2002). Paracoccidioides brasiliensis and paracoccidioidomycosis: molecular approaches to morphogenesis, diagnosis, epidemiology, taxonomy and genetics. Med. Mycol. 40, 225-242. doi: 10.1080/mmy.40.3.225.242

Santana, L. A. D. P., Vainstein, M. H., Tomazett, P. K., Santos-Silva, L. K., Góes, A. M., Schrank, A., et al. (2012). Distinct chitinases are expressed during various growth phases of the human pathogen Paracoccidioides brasiliensis. Mem. Inst. Oswaldo Cruz 107, 310-316. doi: 10.1590/S0074-02762012000300004

Santos, R. D. S., Martelli De Paula, N., Barbosa, M., and De Almeida Soares, C. M. (2012). Caracterização imunológica da proteína recombinante gliceraldeído-3fosfato desidrogenase do patógeno humano Paracoccidioides brasiliensis. SaBios: Rev. Saúde Biol. 7, 35-45.

Sekita, S., Yoshihira, K., Natori, S., Harada, F., Iida, K., and Yahara, I. (1985). Structure-activity relationship of thirty-nine cytochalasans observed in the effects on cellular structures and cellular events and on actin polymerization in vitro. J. Pharmacobiodyn. 8, 906-916.

Sriram, G., Martinez, J. A., Mccabe, E. R., Liao, J. C., and Dipple, K. M. (2005). Single-gene disorders: what role could moonlighting enzymes play? Am. J. Hum. Genet. 76, 911-924. doi: 10.1086/430799

Starnes, G. L., Coincon, M., Sygusch, J., and Sibley, L. D. (2009). Aldolase is essential for energy production and bridging adhesin-actin cytoskeletal interactions during parasite invasion of host cells. Cell Host Microbe 5, 353-364. doi: 10.1016/j.chom.2009.03.005

Straus, A. H., Freymüller, E., Travassos, L. R., and Takahashi, H. K. (1996). Immunochemical and subcellular localization of the $43 \mathrm{kDa}$ glycoprotein antigen of Paracoccidioides brasiliensis with monoclonal antibodies. J. Med. Vet. Mycol. 34, 181-186. doi: 10.1080/02681219680000301

Tatusov, R. L., Koonin, E. V., and Lipman, D. J. (1997). A genomic perspective on protein families. Science 278, 631-637. doi: 10.1126/science.278.5338.631

Tavares, A. H., Silva, S. S., Dantas, A., Campos, E. G., Andrade, R. V., Maranhão, A. Q., et al. (2007). Early transcriptional response of Paracoccidioides brasiliensis upon internalization by murine macrophages. Microbes Infect. 9, 583-590. doi: 10.1016/j.micinf.2007.01.024

Travassos, L. R., and Taborda, C. P. (2012). Paracoccidioidomycosis vaccine. Hum. Vaccin. Immunother. 8, 1450-1453. doi: 10.4161/hv.21283

Troian, R. F. (2009). Caracterização dA Isocitrato Liase e Metilisocitrato Liase do Fungo Patogênico Humano Paracoccidioides brasiliensis. Mestrado, Instituto de Patologia Tropical e Saúde Pública, Universidade Federal de, Goiás.

Tunio, S. A., Oldfield, N. J., Ala'aldeen, D. A., Wooldridge, K. G., and Turner, D. P. (2010). The role of glyceraldehyde 3-phosphate dehydrogenase (GapA-1) in Neisseria meningitidis adherence to human cells. BMC Microbiol. 10:280. doi: 10.1186/1471-2180-10-280

Valenciano, S., Lucas, J. R., Pedregosa, A., Monistrol, I. F., and Laborda, F. (1996). Induction of beta-oxidation enzymes and microbody proliferation in Aspergillus nidulans. Arch. Microbiol. 166, 336-341. doi: 10.1007/s002030050392

Vallejo, M. C., Nakayasu, E. S., Matsuo, A. L., Sobreira, T. J., Longo, L. V., Ganiko, L., et al. (2012). Vesicle and vesicle-free extracellular proteome of Paracoccidioides 
brasiliensis: comparative analysis with other pathogenic fungi. J. Proteome Res. 11, 1676-1685. doi: 10.1021/pr200872s

van Deventer, A. J., van Vliet, H. J., Hop, W. C., and Goessens, W. H. (1994). Diagnostic value of anti-Candida enolase antibodies. J. Clin. Microbiol. 32, 17-23.

Vicentini, A. P., Gesztesi, J. L., Franco, M. F., De Souza, W., De Moraes, J. Z. Travassos, L. R., et al. (1994). Binding of Paracoccidioides brasiliensis to laminin through surface glycoprotein gp43 leads to enhancement of fungal pathogenesis. Infect. Immun. 62, 1465-1469.

Walsh, T. J., Hathorn, J. W., Sobel, J. D., Merz, W. G., Sanchez, V., Maret, S. M., et al. (1991). Detection of circulating candida enolase by immunoassay in patients with cancer and invasive candidiasis. N. Engl. J. Med. 324, 1026-1031. doi: 10.1056/NEJM199104113241504

Wang, G., Xia, Y., Cui, J., Gu, Z., Song, Y., Chen, Y. Q., et al. (2013). The roles of moonlighting proteins in bacteria. Curr. Issues Mol. Biol. 16, 15-22.

Weber, S. S., Parente, A. F. A., Borges, C. L., Parente, J. A., Bailão, A. M., and De Almeida Soares, C. M. (2012). Analysis of the secretomes of Paracoccidioides mycelia and yeast cells. PLoS ONE 7:e52470. doi: 10.1371/journal.pone.0052470

Wienkers, L. C., and Rock, B. (2014). Multienzyme kinetics and sequential metabolism. Methods Mol. Biol. 1113,93-118. doi: 10.1007/978-1-62703-758-7_6

Wierenga, R. K., Kapetaniou, E. G., and Venkatesan, R. (2010). Triosephosphate isomerase: a highly evolved biocatalyst. Cell. Mol. Life Sci. 67, 3961-3982. doi: 10.1007/s00018-010-0473-9

Wistow, G. J., Lietman, T., Williams, L. A., Stapel, S. O., De Jong, W. W., Horwitz, J., et al. (1988). Tau-crystallin/alpha-enolase: one gene encodes both an enzyme and a lens structural protein. J. Cell Biol. 107, 2729-2736. doi: 10.1083/jcb.107. 6.2729

Wolff, A. M., and Arnau, J. (2002). Cloning of glyceraldehyde-3-phosphate dehydrogenase-encoding genes in Mucor circinelloides (Syn. racemosus) and use of the gpdl promoter for recombinant protein production. Fungal Genet. Biol. 35, 21-29. doi: 10.1006/fgbi.2001.1313

Yuan, W., Tuttle, D. L., Shi, Y. J., Ralph, G. S., and Dunn, W. A. (1997) Glucose-induced microautophagy in Pichia pastoris requires the alpha-subunit of phosphofructokinase. J. Cell Sci. 110(Pt 16), 1935-1945.

Zambuzzi-Carvalho, P. F., Cruz, A. H., Santos-Silva, L. K., Goes, A. M., Soares, C. M., and Pereira, M. (2009). The malate synthase of Paracoccidioides brasiliensis $\mathrm{Pb} 01$ is required in the glyoxylate cycle and in the allantoin degradation pathway. Med. Mycol. 47, 734-744. doi: 10.3109/13693780802609620

Conflict of Interest Statement: The authors declare that the research was conducted in the absence of any commercial or financial relationships that could be construed as a potential conflict of interest.

Received: 28 October 2014; accepted: 01 December 2014; published online: 19 December 2014.

Citation: Marcos CM, Oliveira HC, da Silva JF, Assato PA, Fusco-Almeida AM and Mendes-Giannini MJS (2014) The multifaceted roles of metabolic enzymes of the Paracoccidioides species complex. Front. Microbiol. 5:719. doi: 10.3389/fmicb.2014.00719 This article was submitted to Fungi and Their Interactions, a section of the journal Frontiers in Microbiology.

Copyright (C) 2014 Marcos, Oliveira, da Silva, Assato, Fusco-Almeida and MendesGiannini. This is an open-access article distributed under the terms of the Creative Commons Attribution License (CC BY). The use, distribution or reproduction in other forums is permitted, provided the original author(s) or licensor are credited and that the original publication in this journal is cited, in accordance with accepted academic practice. No use, distribution or reproduction is permitted which does not comply with these terms. 